\title{
EMIRO SANDOVAL
}

HUERTAS: METÁFORA DE LA

CRIMINOLOGÍA CRÍTICA EN

COLOMBIA

Jury Vanessa Marulanda Cardona

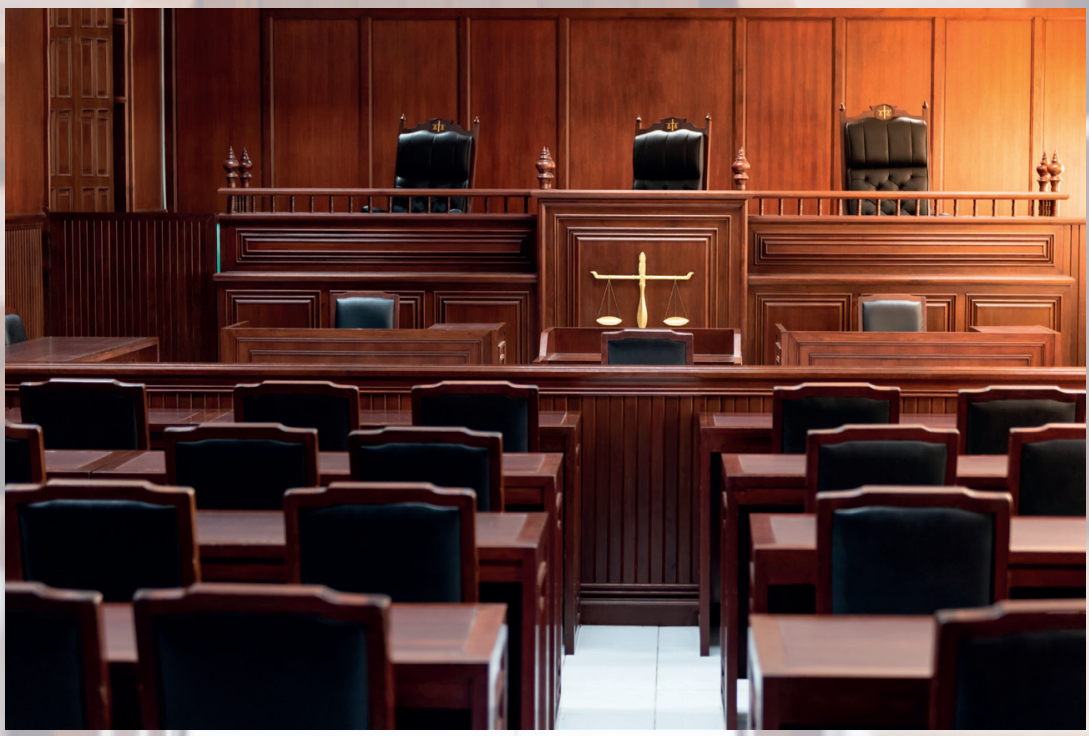





\title{
EMIRO SANDOVAL HUERTAS: METÁFORA DE LA CRIMINOLOGÍA CRÍTICA EN COLOMBIA
}

\author{
Jury Vanessa Marulanda Cardona \\ Universidad DE CALDAS
}

\section{Resumen}

Este documento transita por la criminología crítica, con un abordaje biográfico (como marco metodológico) de Emiro Sandoval Huertas, exmagistrado auxiliar de la Corte Suprema de Justicia, quien murió en los sucesos de la toma y la retoma del Palacio de Justicia en 1985. Tras una breve revisión de la década de 1980 en el país, con sus convulsiones y heridas, se aborda la criminología a manera de recuento, para ahondar en la criminología crítica. Con la muerte de Sandoval Huertas desapareció una figura importantísima para la criminología en Colombia y esto coincide con la aparente desintegración de la criminología crítica como movimiento político que estaba planteando discusiones pertinentes para la concepción social del delito en el país.

Palabras clave: criminología, movimiento político, Emiro Sandoval Huertas, criminología crítica, derecho penal.

La autora: socióloga, estudiante de Derecho. Miembro del grupo de investigación Política criminal, víctima y delito, de la Universidad de Manizales. Correo electrónico: vanessamarulandal@gmail.com

Recibido: 10 de enero de 2020; evaluado: 25 de febrero de 2020; aceptado: 2 de abril de 2020. 


\title{
EMIRO SANDOVAL HUERTAS: METAPHOR OF CRITICAL CRIMINOLOGY IN COLOMBIA
}

\author{
Jury Vanessa Marulanda Cardona \\ Universidad de Caldas
}

\begin{abstract}
This document crosses critical criminology, with a biographical approach of Emiro Sandoval Huertas as a methodological framework. Sandoval Huertas was a former assistant judge of the Supreme Court of Justice, and died in the events of the takeover and retakeover of the Palace of Justice in 1985. After a brief review of the decade of the 1980s in the country, with its convulsions and injuries, the document addresses criminology to delve into critical criminology. With the death of Sandoval Huertas, an incredibly important figure for criminology in Colombia disappeared, and this coincides with the apparent disintegration of critical criminology as a political movement that was posing relevant discussions for the social conception of crime in the country.
\end{abstract}

Keywords: criminology, political movement, Emiro Sandoval Huertas, critical criminology, criminal law.

Author: sociologist, law student. Member of the Criminal policy, victim and crime research group, Universidad de Manizales. Email: vanessamarulandal@gmail.com

Received: January 10, 2020; evaluated: February 25, 2020; accepted: April 2, 2020. 


\title{
EMIRO SANDOVAL HUERTAS: METÁFORA DA CRIMINOLOGIA CRÍTICA NA COLÔMBIA
}

\author{
Jury Vanessa Marulanda Cardona \\ Universidad DE CALDAS
}

\section{Resumo}

Este trabalho transita pela criminologia crítica, com abordagem biográfica (como referencial metodológico) de Emiro Sandoval Huertas, ex-juiz auxiliar da Corte Suprema de Justiça, que morreu na tomada e retomada do Palácio de Justiça da Colômbia em 1985. Após uma breve revisão da década de 1980 no país, com suas convulsões e feridas, a criminologia é abordada de forma narrativa, para aprofundar na criminologia crítica. Com a morte de Sandoval Huertas, desapareceu uma figura importante para essa área na Colômbia e isso coincide com a aparente desintegração da criminologia crítica como movimento político que estava propondo discussões pertinentes para a concepção social do delito no país.

Palavras-chave: criminologia, movimento político, Emiro Sandoval Huertas, criminologia crítica, direito penal.

A autora: socióloga, estudante de direito. Membro do grupo de pesquisa Política criminal, vítima e delito, da Universidad de Manizales. E-mail: vanessamarulanda1@gmail.com

Recebido: 10 de janeiro de 2020; avaliado: 25 de fevereiro de 2020; aceito: 2 de abril de 2020. 


\section{Introducción}

"También, en la inmensa sabiduría, los gorriones se mueren de frío".

La criminología crítica, como movimiento político² en la región latinoamericana, surge en 1981, con el Primer manifiesto de criminólogos críticos, sin desconocer algunas manifestaciones académicas que se gestaron con antelación. Allí se establecieron algunas premisas políticas sobre el marco ideológico que debía caracterizar al grupo, al igual que sus denuncias y sus posibles lineamientos para dar respuesta a la situación del momento y las corrientes criminológicas presentes en el mundo.

El manifiesto "lo elaboraron originalmente Roberto Bergalli, Julio Mayaudon, Emiro Sandoval, y Lola Aniyar de Castro". ${ }^{3}$ Como puede observarse, uno de los autores fue Sandoval Huertas, quien, con sus postulados académicos y planteamientos, se vinculaba a la comprensión de la criminología bajo la lupa del marxismo, como también lo haría el grupo ${ }^{4}$ en algunas de sus posturas.

La prematura muerte de Sandoval en 1985 fue un golpe para los congregados, ya que era uno de los miembros más activos del grupo. El continente se encontraba en convulsiones dictatoriales constantes, conflictos y ráfagas de violencia; la muerte de Emiro Sandoval fue una expresión de ello y se tradujo en la supresión de un pensador con un futuro prometedor y, a pesar de que los criminólogos críticos continuaron su obra independientemente, el grupo, con sus tintes políticos, no continuó como tal en Colombia, pese al segundo manifiesto, diez años después.

Actualmente, el movimiento de criminólogos críticos latinoamericanos se ha transformado en expresiones que nombran la realidad a partir de la academia; el compromiso de militancia política que se había pregonado décadas atrás forma

Juan Carlos Onetti, La muerte y la niña (Bogotá: Alfaguara, 2015), 370.

2 "Hay que subrayar que para un movimiento político, la toma del poder o ejercer presiones sobre el sistema político son fundamentales, éste debe ser un objetivo fijado, a corto, mediano o a largo plazo, pero siempre la meta estará allí, en el logro de ese fin, la toma del poder político o el ejercer presiones sobre el ámbito político para lograr los fines propuestos por el grupo". Se hace énfasis en la presión sobre el sistema político, que era lo que esperaba lograr este grupo. Antonio Tinoco, "Movimientos sociales, movimientos políticos y partidos políticos", Synergies, núm. 4 (2008): 243-259.

3 Lola Aniyar de Castro, Rodrigo Codino y Eugenio Raúl Zaffaroni, Manual de criminología sociopolítica (Buenos Aires: Ediar, 2013), 260

4 Asunto que puede observarse en Emiro Sandoval Huertas, Sistema penal y criminología crítica: el sistema penal colombiano desde la perspectiva de la criminología crítica (Bogotá: Temis, 1985). 
parte del recuerdo. Pese a ello, son obligadas las citas a un grupo de intelectuales que interrogaron su presente de manera que contradecían lo estandarizado.

Para los fines de este trabajo, la metodología utilizada es el abordaje biográfico ${ }^{5}$ reflexivo, desde la palabra de quien no ha tenido cercanía vital con el protagonista, lo cual representa serias limitaciones conceptuales, temporales y experienciales. No obstante, se pretende responder a una búsqueda de revalorización del actor individual como un medio fundamental para la construcción de la memoria colectiva, en línea con el síntoma biográfico ${ }^{6}$ como aquel interés en abordar historias particulares para reconstruir o interpretar hechos históricos. Lo anterior es complementado con notas periodísticas y algunos apuntes descriptivos.

El presente documento da cuenta de cómo la criminología crítica, en tanto acontecer político, vio su ocaso en Colombia con la muerte de Emiro Sandoval Huertas. Para lograrlo, se partirá de un breve contexto de la década en la que murió el exmagistrado auxiliar; luego se hará un tránsito por la criminología, para arribar a la criminología crítica junto con una semblanza de la vida de Sandoval Huertas y se culminará con algunas conclusiones relacionadas con la situación actual de esta disciplina.

\section{Acercamiento a una década}

La década de 1980 significó para Colombia un momento de recrudecimiento del conflicto generalizado. En ese punto se habían consolidado militar y políticamente las guerrillas creadas alrededor de 1964, aparecieron otras de carácter urbano y con diferentes consignas (caso M-19) y una fuerza de contraguerrilla, las Autodefensas unidas de Colombia (AUC) tomó las banderas de quienes rechazaban lo que se tradujera en guerrilla, lucha popular, comunismo, sindicalismo, entre otros. Además, que los carteles dedicados al negocio del narcotráfico emergían como la mayor amenaza para la paz y la convivencia.

El país dejaba atrás los últimos bastiones del Frente Nacional, un acuerdo de alternancia de poder en la jefatura de Estado entre los dos principales partidos políticos, con la intención inicial de evitar un resurgimiento de los aciagos acontecimientos del

Que explora la historia de vida de alguien a partir de documentación y permite establecer trayectorias personales desde fuentes orales o escritas. En Irene Vasilachis de Gialdino, coord., Estrategias de investigación cualitativa (Barcelona: Gedisa, 2006), 177.

$6 \quad$ Joan Pujadas, "El método biográfico y los géneros de la memoria", Revista de antropología social, núm. 9 (2000): 127. 
período histórico que se denominó La Violencia, ${ }^{7}$ una fase de conflicto entre adeptos a los partidos Conservador y Liberal que marcó la primera mitad del siglo XX en Colombia, con algunos matices temporales.

Belisario Betancur, quien fue presidente en 1982, tuvo que encarar una década convulsa: ${ }^{8}$ la toma y la retoma del Palacio de Justicia; el intento de proceso de paz con una de las guerrillas más consolidadas del momento (FARC); ${ }^{9}$ el genocidio del partido político de izquierda Unión Patriótica; las arremetidas de las AUC (masacres, desapariciones y magnicidios, entre otros); el crecimiento desbordado del narcotráfico y su accionar sobre la población. Ello daba la impresión de una conjugación entre el poder, el narcotráfico y ciertos grupos armados en consonancia con un proyecto político relativamente definido. ${ }^{10}$

En este decenio, puntualmente desde 1985, Emiro Sandoval Huertas era magistrado auxiliar de la Corte Suprema de Justicia, personaje que pensaba el derecho penal, la criminología y la penología, como dan cuenta sus clases en la Universidad Externado desde 1978. Su producción académica era hija del espíritu de su tiempo y de su país. En párrafos ulteriores se abordará la disciplina a la que Sandoval dedicó parte de su trayectoria académica, a saber, la criminología.

\section{Breve trasegar de la criminología: pasos previos de la criminología crítica}

Como todos los órdenes cronológicos del nacimiento y transcurso de una disciplina, se presentarán desacuerdos sobre su origen, olvidos, incompatibilidades en cuanto a su primer lugar de enunciación y voces discordes sobre la forma como se nombra (ciencia, disciplina y demás). ${ }^{11}$ La criminología no ha quedado exenta de este tipo de

Respecto a la demarcación temporal: Germán Guzmán Campos, Orlando Fals Borda y Eduardo Umaña Luna, La violencia en Colombia. Tomo I (Bogotá: Punto de Lectura, 2010), 51-52.

8 "El notorio aumento de la violencia política se vio complementado por la violencia resultante de un masivo tráfico de drogas. Mientras tanto, los partidos tradicionales continuaban practicando su habitual juego electoral, mostrando más interés en controlar la votación rural mediante el clientelismo que en ofrecer nuevas políticas y programas". David Bushnell y Montilla Claudia, Colombia. Una Nación a pesar de sí misma: de los tiempos precolombinos a nuestros días (Bogotá: Planeta, 1994), 339.

9 Acuerdos que se intentaron con subsiguientes Gobiernos. Luis Vélez-Rodríguez, Politica criminal y justicia transicional (Valencia: Tirant lo Blanch, 2016), 226.

10 De allí que pueda hablarse de un proyecto de contrainsurgencia, que se expresó con más claridad en esta década. Vilma Liliana Franco, Orden contrainsurgente y dominación (Bogotá: Siglo del hombre, 2009), 175.

11 Discusión en: Massimo Pavarini, "¿Vale la pena salvar la criminología?", Cuadernos de doctrina y jurisprudencia penal 7, núm. 13 (2002): 20. 
discusiones y, por lo tanto, en ciertos momentos ello ha dependido de las posturas académicas que se adopten.

Podría decirse que la criminología se inauguró con el pensamiento ilustrado ${ }^{12}$ y la estructuración de la pena de prisión como resultado de la ruptura del pacto social, por lo que es una expresión del poder soberano. Con la transición del orden medieval al orden burgués, la Revolución Industrial, la constitución de las ciudades más allá de los feudos y demás factores que determinaron el paso hacia la Modernidad, sumados al correlato económico del capitalismo, se estructuró y se consolidó la prisión. ${ }^{13}$

Los primeros compendios de criminología, como la encargada de observar lo que acontece con aquellos que ocupan estas nuevas estructuras disciplinares, se enfocaban en las cualidades del delincuente, con base en los instrumentos de las ciencias naturales y en el método científico hurgando en las causas de la criminalidad; muestra de ello es la publicación de El hombre delincuente, de Cesare Lombroso en 1876, como el primer documento que ahonda en la pregunta etiológica sobre el crimen con fundamento en el positivismo. ${ }^{14}$

Tras considerar la necesidad de la defensa social ante el crimen como la legitimación del derecho penal y del poder punitivo ${ }^{15}$ y estructurar ciertos postulados garantistas, llegó la concepción que abordaba la desviación y sus causas, cuyos exponentes aparecieron en Estados Unidos. Ahora bien, la pregunta sobre la desviación se toma desde diferentes perspectivas: subculturas; ${ }^{16}$ aprendizaje y asociación diferencial; ${ }^{17}$ técnicas de neutralización, ${ }^{18}$ y la teoría del etiquetado (labelling approach), ${ }^{19}$ entre otras.

12 De allí que el crimen, en el marco moderno, se determina por aquellos que no acatan el contrato social, al que cedieron parte de su libertad. Cesare Beccaria y Luigi Ferrajoli, De los delitos y las penas (Bogotá: Temis, 2016), 11 .

13 Massimo Pavarini y Roberto Bergalli, Control y dominación: teorías criminológicas burguesas y proyecto hegemónico (Ciudad de México: Siglo XXI, 1983), 27.

14 Vera Regina Pereira de Andrade, "Do paradigma etiológico ao paradigma da reação social: mudança e permanência de paradigmas criminológicos na ciência e no senso comum", Seqüência: estudos jurídicos e políticos 16, núm. 30 (1995): 26.

15 Lo que Baratta denominaría "ideología de la defensa social". Alessandro Baratta, Criminología crítica y crítica del derecho penal (Buenos Aires: Siglo XXI, 1986), 35.

16 Clifford R. Shaw y de Frederic M. Thrasher.

17 Edwin Sutherland.

18 David Matza.

19 Fundamentado en el interaccionismo simbólico y la etnometodología, volcando la percepción de la desviación como una atribución que las instituciones sociales le dan al sujeto. Baratta, Criminología crítica, 84 . 
La Escuela ecológica de Chicago parte de los postulados de Durkheim sobre la "necesidad" del crimen para el funcionamiento de la sociedad, ${ }^{20}$ con otras precisiones puntuales, en analogía con la forma como se desarrolla la vida vegetal. Esa concepción iba más allá de la pregunta por el sujeto: pasaba por cuestionar la función del territorio y la influencia que tiene su distribución hasta considerar "zonas criminales" y la reacción social ante estas. ${ }^{21}$

Las teorías de la desviación se analizan a partir una perspectiva crítica, desde donde se devela su conservadurismo; esta crítica se hace con base en el conflicto social. ${ }^{22}$ Dichos elementos son, en parte, recogidos por la criminología crítica, como se enuncia a continuación.

\section{Criminología crítica y Emiro Sandoval Huertas}

Emiro Sandoval Huertas nació en 1953, cuando el país culminaba el período de La Violencia y los primeros violentólogos ${ }^{23}$ hacían las veces de criminólogos, en aras de comprender una época enrevesada en diversos aspectos. Era un amante de la academia, ${ }^{24}$ hasta el punto de estudiar becado durante toda su carrera. Obtuvo su grado en Derecho en 1975 y luego, en 1982, consiguió una beca para estudiar su doctorado en Criminología en Alemania (beca Alexander von Humboldt).

Podría decirse que la criminología crítica adquirió este apellido con base en los postulados de la teoría crítica, en una transición de la criminología liberal a la criminología crítica como tal. La Escuela de Frankfurt desarrollaba dicha teoría y sus investigaciones giraban ${ }^{25}$ en torno a la revisión constante de la sociedad, controvirtiendo los ideales pregonados en la Ilustración (que devienen en mito) ${ }^{26}$ desde diversos matices; eran fundamentales tanto la perspectiva revolucionaria que contrariaba todo el conocimiento del momento como una discusión contundente

20 Baratta, Criminología crítica, 57.

21 Ian Taylor et al., La nueva criminología: contribución a una teoría social de la conducta desviada (Buenos Aires: Amorrortu, 1973), 139.

22 Baratta, Criminología crítica, 132.

23 En relación con ello: Julián Andrés Muñoz Tejada, "Expertos y política criminal en Colombia", Política criminal 12, núm. 23 (julio 2017): 285.

24 Laura Jimena Rojas Villamil, "Emiro Sandoval: gigante de la criminología”, Ámbito jurídico, núm. 189 (noviembre de 2005), https://www.ambitojuridico.com/noticias/administrativo-y-contratacion/emirosandoval-gigante-de-la-criminologia (acceso diciembre19, 2020).

25 Rubén Jaramillo Vélez, "Presentación de la teoría crítica de la sociedad", Argumentos 2 (1991): 31.

26 Max Horkheimer y Theodor Adorno, Dialéctica de la ilustración (Madrid: Trotta, 1998), 70. 
sobre la racionalidad instrumental alcanzada por Occidente y tuvo su expresión a lo largo del siglo XX.

De esa fundamentación crítica bebió Emiro Sandoval, pues era un investigador agudo de lo que se presentaba como natural en las ciencias penales. Muestra de ello son sus tres libros publicados a la edad de 32 años:

- Pena privativa de la libertad en Colombia y la Alemania Federal. ${ }^{27}$

- Penología. Parte general y especial. ${ }^{28}$

- Sistema penal y criminología crítica: el sistema penal colombiano desde la perspectiva de la criminología critica. ${ }^{29}$

Asimismo, publicó diversos artículos de investigación. Esta actividad la complementaba con las clases de Penología en la Universidad Externado de Colombia, en las que afiliaba abiertamente su pensamiento a la criminología crítica. ${ }^{30}$ Más adelante, fue elegido como magistrado auxiliar de Alfonso Reyes Echandía, quien fue su maestro en las ciencias penales y pereció junto a él.

En cuanto al rigor de Sandoval, dice Rojas Villamil:

Era un hombre tan consagrado a su oficio, que se levantaba temprano un domingo a sacar una decisión judicial. Decía que no era justo dormir, mientras había un preso que no podía salir de la cárcel sin su fallo. Para él, no había nada antes de tener lista una decisión. Tenía un sentido especial de la justicia. ${ }^{31}$

Por otra parte, uno de los exponentes de la criminología crítica europea fue el italiano Alessandro Baratta con su obra Criminología crítica y crítica del derecho penal, quien se asoció con el grupo latinoamericano ${ }^{32}$ y estableció que:

27 Emiro Sandoval Huertas, Pena privativa en Colombia y la Alemania Federal (Bogotá: Temis, 1988).

28 Emiro Sandoval Huertas, Penología: partes general y especial (Bogotá: Ediciones jurídicas Gustavo Ibáñez, 1998).

29 Sandoval Huertas, Sistema penal.

30 Rojas Villamil, "Emiro Sandoval: Gigante", párr. 9.

31 Rojas Villamil, "Emiro Sandoval: Gigante", párr. 15.

32 Aniyar, Codino y Zaffaroni, Manual, 259. 
Con la perspectiva de la criminología critica, la criminalidad no es ya una cualidad ontológica de determinados comportamientos y de determinados individuos, sino que se revela más bien como un estatus asignado a determinados individuos por medio de una doble selección: en primer lugar, la selección de los bienes protegidos penalmente, $y$ de los comportamientos ofensivos a estos bienes considerados en las figuras legales; en segundo lugar, la selección de los individuos estigmatizados entre todos los individuos que cometen infracciones a normas penalmente sancionadas. ${ }^{33}$

Tres años después de la publicación del texto de Baratta, el 6 de noviembre de 1985 murió Emiro Sandoval Huertas, mientras estaba en el Palacio de Justicia en el ejercicio sus labores como magistrado auxiliar. En medio de las contradicciones de la década, las convulsiones, las heridas y los trajinares que ocasionaron los grupos armados, ocurrió la toma del Palacio por parte del M-19, un grupo guerrillero urbano que deseaba hacer un juicio político al presidente.

Previamente, en 1977, se publicó La nueva criminología, ${ }^{34}$ en la que se exponía el proyecto crítico anglosajón que influenció al latinoamericano, planteó aquello que debía estudiarse en el contexto crítico de la criminología: los orígenes mediatos del acto desviado, los orígenes inmediatos del acto desviado, el acto en sí mismo, los orígenes inmediatos de la reacción social, los orígenes mediatos de la reacción, la influencia de la reacción social en la conducta ulterior, y la naturaleza de la desviación en su conjunto. Allí se observa la introducción de lo político (como distribución cotidiana del poder) y de la política (como ejercicio del poder centralizado) como parte fundamental de la criminología misma: "Una criminología apta para comprender esta evolución y que pueda volver a introducir lo político en el análisis de lo que antes eran cuestiones técnicas tendrá que ocuparse de la sociedad como un todo". ${ }^{35}$

La criminología crítica latinoamericana empezó a desarrollarse principalmente con obras de Rosa del Olmo, Lola Aniyar de Castro, Alfonso Reyes Echandía y José María Rico, entre otros, trabajos permeados e inspirados por los acontecimientos del momento: el Mayo francés, las dictaduras en el Cono Sur, el conflicto armado en Colombia, y el bum latinoamericano, entre otros factores.

El proyecto de criminólogos críticos dio sus primeros pasos en Venezuela, con el Grupo de investigación comparada regional de la Universidad de Zulia, donde

\footnotetext{
Baratta, Criminología crítica, 167.

Taylor et al., La nueva.

Taylor et al., La nueva, 294.
} 
se observaba que la criminología era un acontecimiento político que respondía a cuestionamientos de la América Latina del momento. Una de las tareas fue buscar investigadores que se articularan alrededor de la violencia. ${ }^{36}$ En palabras de Aniyar y Codino, "el proyecto violencia dio más que un resultado: uno teórico, otro sangriento", ${ }^{37}$ al referirse a la muerte o al exilio de algunos de sus investigadores.

El control social también fue un objeto de estudio del grupo naciente, pues este era un factor fundamental en el momento de seleccionar a quienes debían transcurrir por el proceso penitenciario, para crear estereotipos de criminales y enfocarse en clases históricamente vulnerables. Así mismo, los delitos de cuello blanco fueron un foco de análisis para una sección del grupo crítico, dado que en varios países del continente se evidenciaba una fuerte tendencia a la corrupción, que no podía identificarse mediante el control social formal o institucional y no era objeto del derecho penal.

Una de las afirmaciones que fundamentaban el movimiento de los criminólogos críticos sostenía que en países con un mayor desarrollo democrático surgía la criminología y en los que había restricciones y un punitivismo exacerbado florecía el derecho penal. Abogaban por un derecho penal mínimo en algunos casos y, en otros, por la necesidad de replantear la función de la prisión y de las instituciones que intervienen en la aplicación de la política criminal como la policía y las instancias judiciales. De allí que el derecho penal desarrollado en países con mayor control también devenga en crítico.

Los planteamientos del Primer manifiesto de criminólogos críticos expresaban que la división entre países centrales y periféricos definía ciertos delitos, que los mecanismos de represión del Estado también respondían a bases ideológicas y que la criminología ocupaba un papel subalterno. Uno de los objetivos del grupo era la creación de una teoría crítica del control social en América Latina, enfocada en las realidades propias de los países:

En síntesis, para nosotros, la criminología es el saber (conjunto de conocimientos) que nos permite explicar cómo operan los controles sociales punitivos de nuestro margen periférico, qué conductas y actitudes promueven, qué efectos provocan y cómo se los encubre en cuanto ello sea necesario o útil para proyectar

36
37
Aniyar, Codino y Zaffaroni, Manual,
252. 
alternativas a las soluciones punitivas o soluciones punitivas alternativas menos violentas que las existentes y más adecuadas al progreso social. ${ }^{38}$

Emiro Sandoval Huertas murió a sus 32 años, con una obra que se encaminaba a consolidarse, con una carrera que auguraba brillantez y es, en la actualidad, una cita necesaria para los trabajos en criminología crítica, penología y análisis sobre derecho y contextos penitenciarios. Su temprano deceso no ha sido óbice para que sea uno de los más notables representantes del movimiento de criminólogos críticos latinoamericanos y uno de los colombianos más citados al respecto. De allí que, como se afirma en el Prólogo de Penología, en ocasiones la muerte es injusta, "La justicia, compañera de las divinidades del otro mundo, prescribe ese exceso de amor. Ningún derecho lo prescribiría. El derecho no tiene ningún vínculo directo con el amor". ${ }^{39}$

La criminología crítica, como militancia política en Colombia, tuvo su ocaso con la muerte de Emiro Sandoval Huertas, en primer lugar, porque era su principal expositor en el ámbito académico en el momento en que los criminólogos críticos latinoamericanos, incluido él, se organizaron políticamente y, en segundo lugar, porque la criminología crítica en el país pasó a formar parte de la academia y el compromiso político se separó de ella. Podría decirse que la muerte de Emiro Sandoval es una metáfora de cómo se desarrolló la criminología crítica en Colombia en tanto adherencia política.

\section{Conclusiones}

De las 31 universidades públicas que tiene Colombia ninguna oferta Criminología como pregrado. Las Universidades de Antioquia, Colegio Mayor de Cundinamarca, de Nariño, de Sucre, del Atlántico, del Cauca, Industrial de Santander, Militar Nueva Granada, Pedagógica y Tecnológica de Colombia, Popular del Cesar y Surcolombiana la consideran como parte del pénsum de Derecho. Apenas un par de posgrados la mencionan conjugada con el derecho penal o las ciencias penales.

Hoy en día, la criminología está reservada a los grupos de investigación, posgrados y doctorados, pero no hay obligatoriedad de su enseñanza y no aparece como una necesidad en la gama de saberes estandarizados. Este relego académico se trae a

38 Eugenio Raúl Zaffaroni, Criminología: aproximación desde un margen (Bogotá: Temis, 1988), 20.

39 Simone Weil, Giorgio Agamben y José Luis Piquero, La persona y lo sagrado (Madrid: Hermida, 2019), 63. 
colación porque desde allí se puede apuntar a una manifestación política. ${ }^{40}$ Desde esas perspectivas académicas surgen expresiones que cuestionan aspectos elementales para la sociedad: ecología, migración o desaparición de la prisión. Se requiere llevarlo al plano político, ${ }^{41}$ lo cual puede lograrse desde la criminología cautelar. De allí que sea necesario acudir a la reflexión de Zaffaroni ${ }^{42}$ sobre la criminología cautelar, como paso último para la exigencia del uso del poder punitivo con cautela y lograr que la criminología mediática esté al servicio de la criminología académica.

La criminología crítica latinoamericana surgió en un momento de convulsión mundial, debido a la posguerra y a los acontecimientos en los países del continente. Para la criminología, es fundamental vincular la crítica al capitalismo, a la democracia y a los relatos liberales como elementos ligados a la cuestión criminal, pues selecciona, excluye y aparta a los sujetos que se espera procesar. De allí la urgencia de considerar la criminología como una tradición humanística, ${ }^{43}$ crítica de los sistemas de poder.

La vida y la muerte de Emiro Sandoval Huertas son una metáfora de esta agrupación política, que fue brillante en su surgimiento y a la que se le auguraba un futuro de producción crítica que mutaría en consonancia con los acontecimientos políticos y sociales que llegaran con el paso del tiempo. Sin embargo, los grandes mitos — entre ellos, el del comunismo - se fueron fragmentando y la criminología crítica, como suceso político, tuvo su final, aunque no se niegan las diversas manifestaciones que desde la academia se formulan contra un estado de cosas específico.

La necesidad de la criminología no ha cesado; vale la pena salvar la criminología, ${ }^{44}$ pues nuevos discursos que postulan que el criminal nace y es patológicamente peligroso, que existe el gen del crimen o que hay personas que simplemente pueden descartarse, tienen que ser cuestionados y puestos en la discusión pública desde

40 Incluso académicamente se habló de una crisis de la criminología crítica del Norte global: "En los años ochenta el estado de la criminología crítica se caracteriza por cierta confusión, división y desánimo". Elena Larrauri, La herencia de la criminología crítica (Ciudad de México: Siglo XXI, 2009), 191.

${ }^{41}$ Como puede observarse en los planteamientos sobre una criminología desde el Sur, en aras de transformar lo mencionado. Karry Carrington, Russell Hogg y Máximo Sozzo, "Criminología del sur", Delito y sociedad 45, núm. 27 (2018): 11.

42 Eugenio Raúl Zaffaroni, La palabra de los muertos. Conferencias de criminología cautelar (Buenos Aires: Ediar, 2011), 365 .

43 Para ampliar, puede verse: Jorge Restrepo Fontalvo, Criminología: un enfoque humanístico (Bogotá: Temis, 2014).

44 Pavarini, "¿Vale la pena?". 
argumentos criminológicos conjugados con la política criminal y abogar por un paradigma de inclusión ${ }^{45}$ a quienes transitan el proceso penal.

A pesar del ocaso de la criminología crítica como movimiento político, es urgente unir esfuerzos de trabajos aislados sobre el área que permitan retomar la cuestión criminal como un acontecimiento en relación con el poder, útil a un sistema que se renueva y se reinventa con resultados que afectan a quienes se encuentran vulnerables, despojados de rostro, ${ }^{46}$ deshumanizados y apartados, con el fin de que ese ocaso tenga un nuevo amanecer.

\section{Referencias}

Aniyar de Castro, Lola, Rodrigo Codino y Eugenio Raúl Zaffaroni. Manual de criminología sociopolítica. Buenos Aires: Ediar, 2013.

Baratta, Alessandro. Criminología crítica y crítica del derecho penal. Buenos Aires: Siglo XXI, 1986.

Bauman, Zygmunt. Daños colaterales. Desigualdades sociales en la era global. Madrid: Fondo de Cultura Económica, 2011.

Beccaria, Cesare y Luigi Ferrajoli. De los delitos y las penas. Bogotá: Temis, 2016.

Bushnell, David y Claudia Montilla. Colombia. Una Nación a pesar de sí misma: de los tiempos precolombinos a nuestros días. Bogotá: Planeta, 1994.

Carrington, Karry, Russell Hogg y Máximo Sozzo. "Criminología del sur". Delito y sociedad 45, núm. 27 (2018): 9-33.

Diez Ripollés, José Luis. "La dimensión inclusión/exclusión social como guía de la política criminal comparada". Revista electrónica de ciencia penal y criminología, núm. 12-13 (2011): 12-36.

Franco Restrepo, Vilma Liliana. Orden contrainsurgente y dominación. Bogotá: Siglo del Hombre, 2009.

Guzmán Campos, Germán, Orlando Fals Borda y Eduardo Umaña Luna. La violencia en Colombia. Tomo I. Bogotá: Punto de lectura, 2010.

Horkheimer, Max y Theodor Adorno. Dialéctica de la ilustración. Madrid: Trotta, 1998.

Jaramillo Vélez, Rubén. "Presentación de la teoría crítica de la sociedad". Argumentos 2 (1991): 9-87.

Larrauri, Elena. La herencia de la criminología crítica. 2ª ed. Ciudad de México: Siglo XXI, 2009.

45 José Luis Diez Ripollés, "La dimensión inclusión/exclusión social como guía de la política criminal comparada", Revista electrónica de ciencia penal y criminología, núm. 13-12 (2011): 22.

46 Zygmunt Bauman, Daños colaterales. Desigualdades sociales en la era global (Madrid: Fondo de Cultura Económica, 2011), 83. 
Muñoz Tejada, Julián Andrés. "Expertos y política criminal en Colombia”. Política criminal 12, núm. 23 (julio 2017): 267-290.

Pavarini, Massimo y Roberto Bergalli. Control y dominación: teorías criminológicas burguesas y proyecto hegemónico. Ciudad de México: Siglo XXI, 1983.

Pavarini, Massimo. "¿Vale la pena salvar la criminología?". Cuadernos de doctrina y jurisprudencia penal 7, núm. 13 (2002): 15-42.

Pereira de Andrade, Vera Regina. "Do paradigma etiológico ao paradigma da reação social: mudança e permanência de paradigmas criminológicos na ciência e no senso comum". Seqüência: estudos jurídicos e políticos 16, núm. 30 (1995): 24-36.

Pujadas, Joan. "El método biográfico y los géneros de la memoria". Revista de antropología social, núm. 9 (2000): 127-158.

Restrepo Fontalvo, Jorge. Criminología: un enfoque humanístico. Bogotá: Temis, 2014.

Rojas Villamil, Laura Jimena. "Emiro Sandoval: gigante de la criminología”. Ámbito jurídico, núm. 189 (noviembre 2005). https://www.ambitojuridico.com/noticias/administrativoy-contratacion/emiro-sandoval-gigante-de-la-criminologia (acceso diciembre19, 2020).

Sandoval Huertas, Emiro. Pena privativa en Colombia y la Alemania Federal. Bogotá: Temis, 1988.

Sandoval Huertas, Emiro. Penología: partes general y especial. Bogotá: Ediciones jurídicas Gustavo Ibáñez, 1998.

Sandoval Huertas, Emiro. Sistema penal y criminología crítica: el sistema penal colombiano desde la perspectiva de la criminología crítica. Bogotá: Temis, 1985.

Taylor, Ian, Paul Walton, Jock Young y Adolfo Crosa. La nueva criminología: contribución a una teoría social de la conducta desviada. Buenos Aires: Amorrortu, 1973.

Tinoco, Antonio. "Movimientos sociales, movimientos políticos y partidos políticos". Synergies, núm. 4 (2008): 243-259.

Vasilachis de Gialdino, Irene, coord. Estrategias de investigación cualitativa. Barcelona: Gedisa, 2006.

Vélez-Rodríguez, Luis. Política criminal y justicia transicional. Valencia: Tirant lo Blanch, 2016.

Weil, Simone, Giorgio Agamben y José Luis Piquero. La persona y lo sagrado. Madrid: Hermida, 2019.

Zaffaroni, Eugenio Raúl. Criminología: aproximación desde un margen. Bogotá: Temis, 1988.

Zaffaroni, Eugenio Raúl. La palabra de los muertos: conferencias de criminología cautelar. Buenos Aires: Ediar, 2011. 